\title{
Contrast echocardiography: past and present
}

\author{
Josip Vincelj ${ }^{*}$, \\ Sandra Jakšić \\ Jurinjak', \\ Mateja Sabol Pušić \\ 'University of Zagreb School \\ of Medicine, University \\ Hospital Dubrava, Zagreb, \\ Croatia \\ ${ }^{2}$ County Hospital Čakovec, \\ Čakovec, Croatia
}

\begin{abstract}
KEYWORDS: contrast echocardiography, myocardial perfusion, echo contrast agents CITATION: Cardiol Croat. 2017;12(4):144. | https://doi.org/10.15836/ccar2017.144
\end{abstract}

*ADDRESS FOR CORRESPONDENCE: Josip Vincelj, Klinička bolnica Dubrava, Avenija Gojka Šuška 6, HR-10000 Zagreb, Croatia. / Phone: +385-1-2902-444 / E-mail: jvincelj@kbd.hr

ORCID: Josip Vincelj, http://orcid.org/0000-0003-0064-9128 • Sandra Jakšić Jurinjak, http://orcid.org/0000-0002-7349-6137 Mateja Sabol Pušić, http://orcid.org/0000-0003-4895-0681

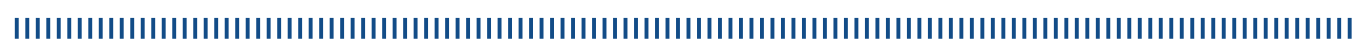

Contrast echocardiography is a noninvasive technique for the assessment of myocardial function and perfusion which improves estimation of endocardial border delineation through ventricular cavity opacification. The first report of contrast echocardiography dates from 1968, when Gramiak and Shah reported their observation of "clouds of bubbles” in the aortic root following injections of saline through an intra-aortic catheter'. The first contrast agents used were indocyanine green, agitated saline solution, sonicated solutions of dextrose and patient's blood, while today we are using second generation contrast agents: perflutren, perfluoropentane, perfluoropropane, perfluorooctylbromide and sulphur hexafluoride. Contrast echocardiography is used for the quantification of heart cavity dimensions, volumes, ejection fraction (EF), assessment of the regional myocardial contractility, detection of blood shunts between cavities and detection of intracardiac masses ${ }^{2}$. It is indicated in the case of suboptimal endocardiac borders display in two or more segments of left ventricle, using the conventional methods. Using the contrast agents with perflutren (Optison ${ }^{\mathrm{TM}}$ ) the endocardial border is visible in more than $93 \%$ of the patients, opacification of the whole left ventricle is achieved in $87 \%$ of the patients. Nowadays, contrast echocardiography has multiple possibilities, from global and regional left ventricle function assessment, to left ventricle shape visualization (Figure 1), detection of intracardiac masses, estimation of myocardial perfusion with differentiation of viable myocardium from stunned and hibernating myocardium, when associated with stress echocardiography ${ }^{3}$.

Many noninvasive diagnostic laboratories are using contrast echocardiography in diagnosing $10-15 \%$ of patients. In conventional echocardiography we can sometimes have difficulties deciding whether some intracardiac mass represents a tumor or thrombus (Figure 1). During contrast echocardiography, if the

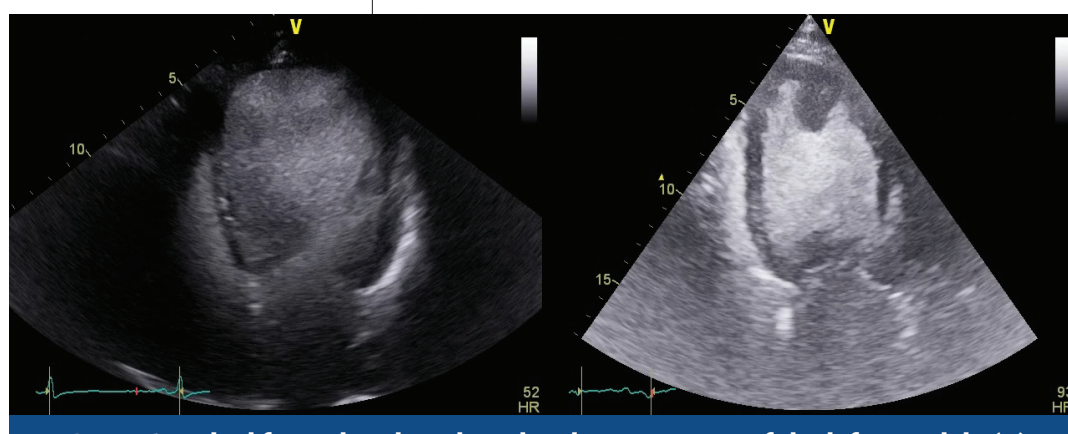

FIGURE 1. Apical four-chamber view showing aneurysm of the left ventricle (A). Left ventricular tumor after administration of the contrast agent OptisonTM (B). mass is without opacification then it represents thrombus because it doesn't take up contrast. But if the mass does opacify through its vascularization, then it is a tumor. Contrast echocardiography can also have a key role during percutaneous ablation of hypertrophic cardiomyopathy in order to choose the target septal branch for IVS thickness reduction and decrease of LV outflow tract gradient to accomplish an optimal clinical and hemodynamic result after the intervention ${ }^{4}$. After many years of investigations, noninvasive assessment of heart cavities and left ventricle myocardial perfusion has become the clinical reality using the contrast echocardiography.
RECEIVED:

March 11, 2017

ACCEPTED:

April 6, 2017

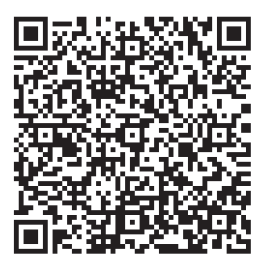

LITERATURE IIIIIIIIIIIIIIIIIIIIIIIIIIIIIIIIIIIIIIIIIIIIIIIIIIIIIIIIIIIIIIIIIIIIIIIIIIIIIIIIIIIIIIIIIIIIIIIIIIIII

1. Gramiak R, Shah PM. Echocardiography of the aortic root. Invest Radiol. 1968 Sep-0ct;3(5):356-66. https://www.ncbi.nlm.nih.gov/pubmed/5688346

2. Kuecherer H. The added clinical value of second generation ultrasound contrast agents. Echocardiography. 2003 Aug;20 Suppl 1:S3-9. https://www.ncbi.nlm.nih.gov/pubmed/23573620

3. Rotaru L, Nanea T. Assessment of myocardial perfusion using contrast echocardiography - Case report. J Med Life. 2015 0ct-Dec;8(4):471-5. https://www.ncbi.nlm.nih.gov/pubmed/26664473

4. Hering D, Welge D, Fassbender D, Horstkotte D, Faber L. Quantitative analysis of intraprocedural myocardial contrast echocardiography during percutaneous septal ablation for hypertrophic obstructive cardiomyopathy. Eur J Echocardiogr. 2004 Dec;5(6):443-8 https://doi.org/10.1016/j.euje.2004.04.003 